\title{
Monetary Policy And Stock Returns: The Case Of Turkey
}

Ramazan Sari (E-mail: rsari@ibu.edu.tr), Abant Izzet Baysal University, Turkey Farooq Malik (E-mail: fum1@psu.edu), Penn State University - Berks Campus

\begin{abstract}
This paper investigates how much of the variance in stock returns can be explained by monetary policy for the case of Turkey. We extend the work of Ewing (2001a) for the case of Turkey by using the newly developed generalized forecast error variance decomposition technique [Koop et al. (1996), Pesaran and Shin (1998)]. Results suggest that the growth rate of money supply contain significant information for predicting variance of future forecast errors of stock returns. The results provide information which is important for building accurate asset pricing models, forecasting future stock market volatility and furthers our understanding of stock market behavior in Turkey.
\end{abstract}

\subsection{Introduction}

$T$

he relationship between monetary variables and stock returns has been a central issue in a growing body of research in the area of finance. Although majority of the research have focused on the impact of the monetary policy on real sector [Romer and Romer (1989); Bernanke and Blinder (1988), (1992); Stockman (1988); Gertler and Gilchrist (1994)], the impact on stock returns has recently been a subject of a series of empirical studies [Thorbecke (1997); Patelis (1997); Ewing (2001a); Booth and Booth (1997)].

There are quite a few studies on the effect of monetary policy on stock returns for the case of U.S. Thorbecke (1997) argue that stock prices are the expected present value of the future net cash flows and expansionary monetary policy exerts real effects on the economy by increasing future net cash flows or by decreasing present discount factors. Waud (1970) concludes that the changes in discount rate provide information whether the changes in bank credit and money are consistent with the cash flow needs of the economy. Cook and Hahn (1988) contend that the U.S. stock market reacts negatively to increases in discount rate and positively to decreases in discount rate. Employing generalized variance decomposition methodology within a vector autoregression (VAR) framework, Ewing (2001a) provides evidence that monetary policy has a considerable impact on stock returns for the case of U.S. Ewing (2001b) studies the transmission of shocks among state variables using stance of monetary policy, risk premia, real output and stock returns. He finds that a shock to monetary policy variable affects the economy through its effects on risk of default and documents that unanticipated changes in growth are associated with changes in monetary policy.

Surprisingly, very few studies have examined the interaction of monetary variables with stock returns for the case of Turkey. Metin and Muradoglu (2000) study how stock prices of Istanbul Stock Exchange are affected by money supply, inflation rate, interest rates, exchange rates, and budget deficits. They use VAR and ECM (Error Correction Model) and conclude that ECM performs better in out of sample forecasts of stock prices. Kargi and Terzi (1997) using a VAR model document that inflation explain a considerable portion of variance of stock returns and interest rates explain a large portion of variance in inflation.

In this paper, we investigate the impact of monetary policy on stock returns in Turkey. Specifically, we examine how much of the variance in stock returns from Istanbul Stock Exchange can be explained by the growth

Readers with comments or questions are encouraged to contact the authors via email. 
rate of money supply, which is used as a measure to gauge the stance of monetary policy. A unique feature of this paper is that we use the recently developed generalized forecast error variance decomposition technique of Koop et al. (1996) and Pesaran and Shin (1998) to determine the information content of the growth rate of money supply. All previous studies that used VAR models and innovation accounting techniques for the case of Turkey are subject to the "orthogonality" critique of Lutkenpohl (1991), the generalized method provides superior results as compared to the standard technique and also allows us to determine the initial impact that unanticipated changes in the growth rate of money supply have on the growth rate of stock returns.

In the standard methodology, results are typically sensitive to the order in which the variables are entered into the VAR. However, a problem arises if the variables in the VAR are contemporaneously correlated. Because the Cholesky decomposition is used to orthogonalize the shocks, the researcher is forced to restrict the VAR in such a fashion that at least one variable has no contemporaneous effect on another. The extent to which this assumption (i.e., the restriction) is violated determines how sensitive the results are to a re-ordering of the variables in the VAR. The new method developed by Koop et al. (1996) and Pesaran and Shin (1998) provides robust results regardless of how the variables are ordered in the model. These generalized decompositions allow us to make robust comparisons about the extent of information contained in the shocks to each of the variables in the system about the forecast error variance of growth of stock returns at different forecasting horizons.

The rest of the paper is outlined as follows: Section II explains the data and methodology, section III reports the results, section IV provides conclusion, and section $\mathrm{V}$ offers suggestions for future research.

\subsection{Data and Methodology}

In order to determine if the monetary variable contain significant information about future movements in stock market returns in Turkey, we examine monthly data covering the period from January 1987 to September 2000. ${ }^{1}$ Istanbul Stock Exchange 100 index is used to measure stock prices. Industrial production index is used to measure real output activity. We use seasonally adjusted M1 and M2 to measure money supply. ${ }^{2}$ All data are obtained from the Central Bank of Turkey. Consumer price index is used to capture general price level. All series contain unit root in level form and thus growth rates were used in the analysis. ${ }^{3}$

We compute the newly developed generalized forecast error variance decompositions of Koop et al. (1996) and Pesaran and Shin (1998). Forecast error variance decompositions show the proportion of the movements in a sequence due to its "own" shocks versus shocks to the other variables in the system. The traditional method has been criticized for the "orthogonality assumption" as results may differ considerably depending on how the variables are ordered in the VAR. Furthermore, if shocks to one equation in the VAR have small contemporaneous effect on some variable but affect the sequence with a lag then one expects only a small proportion of the forecast error variance to be explained by these shocks in short horizons and a greater proportion in longer horizons. Results using the orthogonalized method reveal that in very short horizons most of the forecast error variance is explained by the variable itself and a very small fraction is explained in long horizons. Cholesky decomposition is used to orthogonalize the shocks in the traditional method and it forces all of the forecast error variance to be explained by its own shock in the first time period. The orthogonalized method may give very different results especially at short horizons if variables are re-ordered.

The generalized forecast error variance decomposition developed by Koop et al. (1996) and Pesaran and Shin (1998) does not depend on the ordering of the variables and does not orthogonalize the shocks before computing the variance decompositions.

The following discussion is attributed to Pesaran and Pesaran (1997) and gives a brief summary of the generalized decomposition methodology. A VAR (p) model is typically written as $\mathbf{r}_{\mathrm{t}}=\mathbf{A} \mathbf{y}_{\mathrm{t}}+\mathbf{e}_{\mathrm{t}}$, where $\mathrm{t}=1,2$, $\ldots \mathrm{n}, \mathbf{y}_{\mathrm{t}}=\left(1, \mathbf{y}_{\mathrm{t}-1}, \mathbf{y}_{\mathrm{t}-2}, \ldots, \mathbf{y}_{\mathrm{t}-\mathrm{p}}\right)$ and $\mathbf{r}_{\mathrm{t}}$ is an $\mathrm{m} \times 1$ vector. Here the disturbances are well-behaved white-noise processes with covariance matrix $\boldsymbol{\Sigma}$, the regressors are not perfectly collinear and all variables are generated by a stationary process. The VAR can be represented by an infinite MA representation given as: 
1) $\quad \mathbf{r}_{\mathrm{t}}=\Sigma_{\mathrm{j}=0}^{\infty} \mathbf{A}_{\mathrm{j}} \mathbf{e}_{\mathrm{t}-\mathrm{j}}$

where $\mathbf{A}_{\mathrm{j}}=\boldsymbol{\Phi}_{1} \mathbf{A}_{\mathrm{j}-1}+\boldsymbol{\Phi}_{2} \mathbf{A}_{\mathrm{j}-2}+\ldots+\boldsymbol{\Phi}_{\mathrm{p}} \mathbf{A}_{\mathrm{j}-\mathrm{p}}, \mathbf{j}=1,2, \ldots$, with $\mathbf{A}_{0}=\mathbf{I}_{\mathrm{m}}$ and $\mathbf{A}_{\mathrm{j}}=\mathbf{0}$ for $\mathrm{j}<0$.

The forecast error of predicting $\mathbf{r}_{\mathrm{t}+\mathrm{N}}$ conditional on information given at time $\mathrm{t}-1$ is given by $\xi_{\mathrm{t}}(\mathrm{N})=$ $\sum_{\mathrm{k}=0}{ }^{\mathrm{N}} \mathbf{A}_{\mathrm{k}} \mathbf{e}_{\mathrm{t}+\mathrm{N}-\mathrm{k}}$, where $\boldsymbol{\xi}_{\mathrm{t}}(\mathrm{N})$ is $\mathrm{m} \times 1$, and the forecast error covariance matrix is given as $\operatorname{Cov}\left[\boldsymbol{\xi}_{\mathrm{t}}(\mathrm{N})\right]=\sum_{\mathrm{k}=0}{ }^{\mathrm{N}} \mathbf{A}_{\mathrm{k}} \boldsymbol{\Sigma} \mathbf{A}_{\mathrm{k}}{ }^{\prime}$. The forecast error covariance matrix of predicting $\mathbf{r}_{\mathrm{t}+\mathrm{N}}$ conditional on information at time $\mathrm{t}-1$ is $\xi_{\mathrm{t}}^{(\mathrm{i})}(\mathrm{N})=$ $\sum_{\mathrm{k}=0} \mathrm{~N}_{\mathrm{k}}\left(\mathbf{e}_{\mathrm{t}+\mathrm{N}-\mathrm{k}}-\mathrm{E}\left(\mathrm{e}_{\mathrm{t}+\mathrm{N}-\mathrm{k}} \mid \mathrm{e}_{\mathrm{i}, t+\mathrm{N}-\mathrm{k}}\right)\right)$ assuming given values of the shocks to the $\mathrm{i}^{\text {th }}$ equation $\left(\mathrm{e}_{\mathrm{i}, t}, \mathrm{e}_{\mathrm{i}, \mathrm{t}+1}, \ldots, \mathrm{e}_{\mathrm{i}, \mathrm{t}+\mathrm{N}}\right)$.

Assume $\mathrm{E}\left(\mathbf{e}_{\mathrm{t}} \mid \mathrm{u}_{\mathrm{i}, \mathrm{t}}=\delta_{\mathrm{i}}\right)=\left(\sigma_{\mathrm{li}}, \sigma_{2 \mathrm{i}}, \ldots, \sigma_{\mathrm{mi}}\right)^{\prime} \sigma_{\mathrm{ii}}^{-1} \delta_{\mathrm{i}}$ and $\mathbf{e}_{\mathrm{t}} \sim \mathrm{N}(0, \boldsymbol{\Sigma})$, where $\delta_{\mathrm{i}}=\left(\sigma_{\mathrm{ii}}\right)^{-1 / 2}$ denotes a unit standard deviation shock. This results in $\mathrm{E}\left(\mathbf{e}_{\mathrm{t}+\mathrm{N}-\mathrm{k}} \mid \mathrm{e}_{\mathrm{i}, t+\mathrm{N}-\mathrm{k}}\right)=\left(\sigma_{\mathrm{ii}}{ }^{-1} \Sigma \mathbf{u}_{\mathrm{i}}\right) \mathrm{e}_{\mathrm{i}, t+\mathrm{N}-\mathrm{k}}$ for $\mathrm{i}=1,2, \ldots \mathrm{m}$ and $\mathrm{k}=1,2, \ldots \mathrm{N}$, with $\mathbf{u}_{\mathrm{i}}$ being $\mathrm{m} \times 1$ vector with ith element equal to one and all other elements are zero. Substitution and taking conditional expectations results in:

$$
\operatorname{Cov}\left[\xi_{\mathrm{t}}^{(\mathrm{i})}(\mathrm{N})\right]=\sum_{\mathrm{k}=0}{ }^{\mathrm{N}} \mathbf{A}_{\mathrm{k}} \boldsymbol{\Sigma} \mathbf{A}_{\mathrm{k}}{ }^{\prime}-\sigma_{\mathrm{ii}}{ }^{-1}\left(\sum_{\mathrm{k}=0}{ }^{\mathrm{N}} \mathbf{A}_{\mathrm{k}} \boldsymbol{\Sigma} \mathbf{u}_{\mathrm{i}} \mathbf{u}_{\mathrm{i}}{ }^{\prime} \boldsymbol{\Sigma} \mathbf{A}_{\mathrm{k}}{ }^{\prime}\right)
$$

Conditioning on the future shocks to the $\mathrm{i}^{\text {th }}$ equation will show us the decrease in the $\mathrm{N}$-step forecast error variance of $\mathbf{x}_{t}$ and is given as:

$$
\Delta_{\mathrm{iN}}=\operatorname{Cov}\left[\xi_{\mathrm{t}}(\mathrm{N})\right]-\operatorname{Cov}\left[\xi_{\mathrm{t}}^{(\mathrm{i})}(\mathrm{N})\right]=\sigma_{\mathrm{ii}}{ }^{-1} \sum_{\mathrm{k}=0}{ }^{\mathrm{N}} \mathbf{A}_{\mathrm{k}} \boldsymbol{\Sigma} \mathbf{u}_{\mathrm{i}} \mathbf{u}_{\mathrm{i}}^{\prime} \boldsymbol{\Sigma} \mathbf{A}_{\mathrm{k}}{ }^{\prime}
$$

The generalized forecast error variance decomposition results by scaling the $\mathrm{j}^{\text {th }}$ element by the $\mathrm{N}$-step ahead forecast error variance of the $\mathrm{i}^{\text {th }}$ variable in $\mathbf{x}_{\mathrm{t}}$ and is given as:

$$
\Psi_{\mathrm{ij}, \mathrm{N}}=\left[\sigma_{\mathrm{ii}}^{-1} \Sigma_{\mathrm{k}=0}^{\mathrm{N}}\left(\mathbf{u}_{\mathrm{j}} \mathbf{A}_{\mathrm{k}} \boldsymbol{\Sigma} \mathbf{u}_{\mathrm{i}}\right)^{2}\right] /\left[\Sigma_{\mathrm{k}=0} \mathrm{~N}^{\mathrm{N}} \mathbf{u}_{\mathrm{i}} \mathbf{A}_{\mathrm{k}} \boldsymbol{\Sigma} \mathbf{A}_{\mathrm{k}} \mathbf{u}_{\mathrm{i}}\right]
$$

The generalized variance decompositions given in equation (4) does not change when variables are reordered in the VAR and also measure the effects of other variables on forecast variance at zero time horizon.

First, we estimate a vector autoregression that contains growth rate of stock prices (RETURN), growth rate of consumer price index (INF), growth rate of industrial production index (GIP) and growth rate of M1 (GM1). We refer to this specification as VAR1. Second, we re-estimate the model by replacing M1 with M2 and we refer to this specification as VAR2. ${ }^{4}$ The order of VAR1 and VAR2 was determined to be 5 and 4, respectively, based on Akaike's information criterion (AIC).

Before proceeding to an examination of the forecast error variance decompositions of stock returns, we performed a test to determine if shocks were contemporaneously correlated in the individual equations that make up the VAR. Specifically, we tested the null hypothesis that the off-diagonal elements in the covariance matrix equal zero against the alternative hypothesis that at least one of the off-diagonal elements have a non-zero value. The loglikelihood ratio test statistic distributed as $\chi^{2}$ is given as $L R=2\left(L_{u}-L_{r}\right)$ where $L_{u}$ and $L_{r}$ are the maximized values for the log-likelihood functions for the case of unrestricted and restricted models, respectively. ${ }^{5}$ In our case the log-likelihood ratio test statistic with 4 degrees of freedom was 28.89 and 14.53 for VAR1 and VAR2, respectively, both significant at less than the $1 \%$ level. This suggests that the assumption that all off-diagonal elements in the covariance matrix are zero is strongly rejected for both VARs in our case and therefore we use the generalized forecast error variance decompositions in our analysis.

\subsection{Results}

The results for the generalized forecast error variance decompositions are shown in Table 1. Note that, unlike the orthogonalized case, the row values for the generalized decompositions do not have to sum to 1.00. The generalized version gives an "optimal" measure of the amount of forecast error variance decomposition for each variable like an average of the decomposition values that would result from various ways in which one could possibly order the variables. 
Table 1: Generalized Forecast Error Variance Decompositions of Stock Returns in Turkey

Panel A: VAR1

\begin{tabular}{ccccc}
\hline Horizon & GM1 & INF & RETURN & GIP \\
\hline 0 & .009644 & .007414 & 1.0000 & .013382 \\
1 & .024800 & .015346 & .97242 & .018719 \\
2 & .024828 & .021838 & .96061 & .023678 \\
3 & .030558 & .023086 & .94890 & .024818 \\
4 & .030273 & .029485 & .92922 & .034314 \\
5 & .030471 & .036193 & .91616 & .036630 \\
6 & .030303 & .037971 & .91359 & .036343 \\
7 & .030936 & .037978 & .91276 & .036307 \\
8 & .031097 & .038535 & .91198 & .036275 \\
9 & .031905 & .040490 & .90904 & .036249 \\
10 & .033131 & .042347 & .90583 & .036142 \\
11 & .033297 & .043913 & .90429 & .036138 \\
12 & .034050 & .044372 & .90324 & .036080 \\
\hline
\end{tabular}

Panel B: VAR2

\begin{tabular}{ccccc}
\hline Horizon & GM2 & INF & RETURN & GIP \\
\hline 0 & .010235 & .002434 & 1.0000 & .008117 \\
1 & .019990 & .022546 & .96599 & .015287 \\
2 & .020158 & .024736 & .95450 & .023880 \\
3 & .024157 & .027071 & .94688 & .024481 \\
4 & .025493 & .029315 & .93190 & .033380 \\
5 & .025658 & .035956 & .92483 & .034014 \\
6 & .028250 & .043191 & .91537 & .033668 \\
7 & .029021 & .043529 & .91409 & .034138 \\
8 & .030078 & .044049 & .91266 & .034095 \\
9 & .031288 & .046026 & .90900 & .034351 \\
10 & .032579 & .049543 & .90436 & .034178 \\
11 & .033356 & .053452 & .89978 & .034003 \\
12 & .033912 & .055346 & .89744 & .033927 \\
\hline \multicolumn{2}{l}{ Notes: The forecast horizon is measured in months. The order of VAR1 and VAR2 was 5 and 4, } \\
respectively, and was determined based on Akaike's information criterion (AIC).
\end{tabular}

For VAR1 (see Panel A), it is interesting to note that growth rate of money supply (GM1), growth rate of price level (INF) and the growth rate of industrial production (GIP), each explain more than 0.03 (i.e., 3\%) of the forecast error variance of RETURN at the 12-month horizon. Furthermore, unlike orthogonalized decompositions, the generalized method allows us to determine the initial impact effects. However, both shocks to GM1 and GIP provide more significant amount of information as to the forecast error variance of RETURN at initial impact as compared to INF. However, except at the initial impact, inflation has the largest impact at each horizon.

As a check of robustness, we re-estimated the VAR (see Panel B) by replacing the M1 variable with M2. The results are not significantly affected which suggests that our results are not sensitive to the particular measure of money supply used. ${ }^{6}$ Generally speaking, the variance decompositions reported in Table 1 suggest that monetary policy has a considerable impact on stock market returns in Turkey.

\subsection{Conclusion}

This paper examined the impact of monetary policy on stock returns for the case of Turkey. Using growth rates of money supply as a proxy for monetary policy in a vector autoregression framework, we find that a shock to growth rate of money supply contain significant information for predicting variance in future forecast errors of stock 
returns. Inflation and growth in industrial production also play a key role in determination of variance of stock returns. Unlike all previous studies using Turkish data, the paper further adds to the literature on the subject by using the recently developed generalized forecast error variance decomposition technique of Koop et al. (1996) and Pesaran and Shin (1998). Our results are in line with evidence from studies using data from United States. For example, Ewing (2001a) also finds that inflation explains the largest variance in stock returns while monetary policy variable and real output growth, both share the second place. Our robust results provide information which is important for building accurate asset pricing models and forecasting future stock market volatility. Also, monetary policy makers are keen to know the effects of monetary policy on stock returns as recent evidence suggests (see Ewing 2001b) strong effects of stock market behavior on real economic activity.

\subsection{Suggestions for Future Research}

The present paper suggest two avenues of future research based on our finding that growth rate of money supply contain significant information for predicting future variance of stock returns. First, it would be interesting to know if the results hold true for other developing countries. Second, our model for those developing countries could be augmented by adding a variable that would capture performance of a big trading partner. The results could be important for policy makers.

\section{Endnotes}

1. This ending date was chosen because Turkey experienced severe stock market crises in September 2000. Recent evidence suggests that market behavior is different in pre- and post-crash periods [Lee and Kim (1993); Choudhry (1996)]. Thus, we include only pre-crash period in our analysis.

2. Analogous to U.S., M1 includes currency plus demand deposits and M2 includes M1 plus time deposits.

3. Growth rates are calculated as the first difference of natural logarithms. Results of unit root tests are available on request.

4. Log-likelihood ratio test of block Granger non-causality for each VAR was also performed. The null hypothesis that for RETURN equation, all the coefficients of lagged variables (except RETURN) on right hand side are equal to zero was rejected at less than 5\% significance level for both VARs.

5. $\mathrm{LL}_{\mathrm{u}}$ is the system log-likelihood from the VAR and $\mathrm{LL}_{\mathrm{r}}$ is the sum of the log-likelihood values from the individual equations comprising the VAR.

6. We also estimated a VAR by including growth rate of exchange rate (against U.S. Dollar) as an additional endogenous variable. It had insignificant effect on our results. Results are available on request.

\section{References}

1. Bernanke, B. and A. Blinder, "The Federal Funds Rate and the Channels of Monetary Policy," American Economic Review, Vol. 82, pp. 901-22, 1992.

2. Bernanke, B. and A. Blinder, "Credit, Money, and Aggregate Demand," American Economic Review, Vol. 78, pp. 435-39, 1988.

3. Booth, J. R. and L. C. Booth, "Economic Factors, Monetary Policy, and Expected Returns on Stocks and Bonds," FRBSF Economic Review, Vol. 2, pp. 32-42, 1997.

4. Choudhry, T., "Stock Market Volatility and the Crash of 1987: Evidence from Six Emerging Markets," Journal of International Money and Finance, Vol. 15, pp. 969-81, 1996.

5. Cook, T. and T. Hahn, "The Information Content of Discount Rate Announcements and their Effect on Market Interest Rates," Journal of Money, Credit, and Banking, Vol. 20, pp. 167-80, 1988.

6. Ewing, B. T., "Monetary Policy and Stock Returns," Bulletin of Economic Research, Vol. 53, pp.73-79, 2001a.

7. Ewing, B. T., "Cross-Effects of Fundamental State Variables," Journal of Macroeconomics, Vol. 23, pp633-645, 2001b.

8. Gertler, M. and S. Gilchrist, "Monetary Policy, Business Cycles, and the Behavior of Small Manufacturing Firms," Quarterly Journal of Economics, Vol. 109, pp. 309-340, 1994. 
9. Kargi, N and H. Terzi, "Causal Relations Among the ISE, Inflation, Interest Rates and Real Activity in Turkey: A VAR Analysis,” ISE Review, Vol. 1, pp. 27-38, 1997.

10. Koop, G., M. H. Pesaran and S. M. Potter, "Impulse Response Analysis in Nonlinear Multivariate Models," Journal of Econometrics, Vol. 74, pp. 119-47, 1996.

11. Lee, S. B. and K. J. Kim, "Does the October 1987 Crash Strengthen the Co-movements Among National Stock Markets?" Review of Financial Economics, Vol. 3, pp. 89-102, 1993.

12. Lutkenpohl, H., Introduction to Multiple Time Series Analysis, Springer-Verlag, Berlin, 1991.

13. Metin, K. and G. Muradoglu, "Forecasting Stock Prices by Using Alternative Time Series Models", ISE Review, Vol. 4, pp. 17-24, 2000.

14. Patelis, A., "Stock Return Predictability and the Role of Monetary Policy," Journal of Finance, Vol. 52, pp. 1951-72, 1997.

15. Pesaran, M. H. and B. Pesaran, Working with Microfit 4.0, Camfit Data Ltd., Cambridge, England, 1997.

16. Pesaran, M. H. and Y. Shin, "Generalized Impulse Response Analysis in Linear Multivariate Models," Economics Letters, Vol. 58, pp.17-29, 1998.

17. Romer, C. and D. Romer, "Does Monetary Policy Matter? A New Test in the Spirit of Friedman and Schwartz," National Bureau of Economic Research Working Paper, 2966, 1989.

18. Stockman, A., "Sectoral and National Aggregate Disturbances to Industrial Output in Seven European Countries," Journal of Monetary Economics, Vol. 21, pp. 387-409, 1988.

19. Thorbecke, W., "On Stock Market Returns and Monetary Policy,” Journal of Finance, Vol. 52, pp. 638-54, 1997.

20. Waud, R., "Public Interpretation of Federal Reserve Discount Rate Changes: Evidence on the “Announcement Effect," Econometrica, pp. 321-50, Vol 38, 1970.

Notes 